\title{
Determinants of Accounts Receivable Level: Portfolio Approach in Firm's Trade Credit Policy
}

\author{
Grzegorz Michalski*
}

\section{Introduction}

The basic financial aim of an enterprise is maximization of its value. At the same time, both theoretical and practical meaning is researched for determinants that increase the enterprise value. Financial literature contains information about numerous factors that influence enterprise value. Among those contributing factors is the extent of the net working capital and the elements shaping it, such as the level of cash tied up in accounts receivable, inventories, the early settlement of accounts payable, and operational cash balances. The greater part of classic financial models and proposals relating to optimum current assets management was constructed with net profit maximization in mind. This is the reason why these models need reconstruction in order to make them suitable to firms that want to maximize their value.

\section{Literature Review}

The decision whether to extend the trade credit terms, is a compromise between limiting the risk of allowing for the payment postponement from unreliable purchasers and gaining new customers by way of a more liberal enterprise trade credit policy. This decision shapes the level and quality of accounts receivable. Robichek (Robichek, 1965) discus risk involved to accounts receivable decisions, which must be accepted by financial institutions pledging o accounts receivable of the firm. Smith (Smith, 1973) predicts that portfolio theory may be used to decrease accounts receivable risk. Friedland (Friedland, 1966) agree with that current assets could be viewed in portfolio context. Pringle and Cohn (Pringle, 1974) even try to adapt the CAPM theory to working capital elements. Bierman and Hausman (Bierman, 1970) discuss the granting policy of a firm and shows that trade credit policy requires balancing the future sales gains against possible losses. Lewellen, Johnson and Edmister (Lewellen, 1972; Lewellen, 1973) explain how and why traditional devices used for monitoring accounts receivable should be changed by new and better ones. Freitas (Freitas, 1973) shows relation between liquidity and risk during accounts receivable management.

The question discussed in this article concerns the possibility of using portfolio theory in making decisions about selecting which customers should be given trade credit. In this article, we will show that it is possible that the firm sells on trade credit terms to some customers, who were previously rejected because of too great an operational risk, with a positive outcome on the creation of increased firm value. This extension of trade credit is possible

\footnotetext{
* Dr Grzegorz Michalski, Assistant Professor, Department of Corporate Finance and Value Management, Wroclaw University of Economics, Wroclaw, Poland, ul. Komandorska 118/120, p. Z- 2, KFPiZW; PL53-345 Wrocław, Poland, tel. 0048713680747, fax 0048717181717, Grzegorz.Michalski@ae.wroc.pl; http://michalskig.com/.
} 
only if the firm has purchasers from various branches, and if these branches have different levels of operating risk. The key to success for a firm is to perform portfolio analysis with the result of a varied portfolio of customers with a spectrum of managed levels of operating risk.

\section{Management of Accounts Receivable with Value Maximization as AIM}

If holding accounts receivable on a level defined by the enterprise provides greater advantages than negative influence, the firm value will grow. Changes in the level of accounts receivable affect on the value of the firm. To measure the effects that these changes produce, we use the following formula, which is based on the assumption that the firm present value is the sum of the future free cash flows to the firm $(F C F F)$, discounted by the rate of the cost of capital financing the firm:

$$
\Delta V_{p}=\sum_{t=1}^{n} \frac{\Delta F C F F_{t}}{(1+k)^{t}},
$$

where $\Delta V_{p}=$ firm value increase; $\triangle F C F F_{t}=$ future free cash flow growth in period $t$; and $k=$ discount rate ${ }^{1}$.

During estimation of the free cash flows, the holding and increasing of net working capital ties up money used for financing net working capital. If net working capital increases, the firm must utilize and tie up more money, and this decreases free cash flows. Production level growth necessitates increased levels of cash, inventories, and accounts receivable. A part of this growth will be covered with current liabilities that automatically grow with the growth of production and sales. The remaining cash requirements (that are noted as net working capital growth, $\triangle N W C$ ) will require a different form of financing.

Trade credit policy decisions changing the terms of trade credit create a new accounts receivable level. Consequently, trade credit policy has an influence on firm value. This comes as a result of alternative costs of money tied in accounts receivable and general costs associated with managing accounts receivable. Both the first and the second involve modification of future free cash flows and as a consequence the firm value changes. In Figure 1, we show the influence of trade credit policy changes on firm value. These decisions change:

- future free cash flows $(F C F F)$,

- life of the firm $(t)$ and

- rate of the cost of capital financing the firm $(k)$.

Changes to these three components influence the creation of the firm value $\left(\Delta V_{p}\right)$.

1 To estimate changes in accounts receivable levels, we accept discount rate equal to the average weighted cost of capital (WACC). Such changes and their results are strategic and long term in their character, although they refer to accounts receivable and short run area decisions, see: (Maness, Zietlow, 1998, pp. 62-63). 
Fig. 1 The trade credit policy influence on firm value

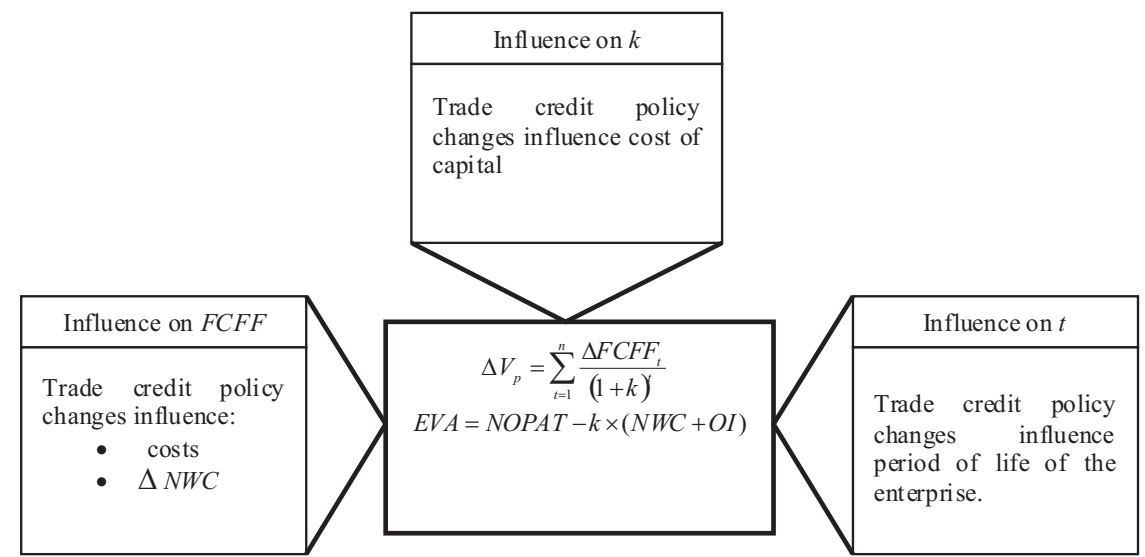

where $F C F F=$ free cash flows to firm; $\triangle N W C=$ net working capital growth; $k=$ cost of the capital financing the firm; and $t=$ the lifetime of the firm and time to generate single $F C F F$.

Source: own study

Accounts receivable changes (resulting from changes in trade credit policy of the firm) affect the net working capital level and also the level of accounts receivable management operating costs in a firm; these operating costs are a result of accounts receivable level monitoring and recovery charges).

Trade credit terms give evidence about a firm trade credit policy. They are the parameters of trade credit and include:

- the maximum delay in payment by purchasers (trade credit period);

- the time the purchaser has to pay with a cash discount; and

- the rate of the cash discount

The length of the cash discount period and the maximum delay in payment by purchasers give information about the character of a firm trade credit policy. These trade credit conditions are:

$$
\text { ps los, net } o k
$$

where $p s=$ cash discount rate, $o s=$ cash discount period, and $o k=$ maximum payment delay period.

The terms of a trade credit sale are the result of a firm's management decision made on the basis of information about factors such as:

- market competition,

- the kind of goods or services offered,

- seasonality and elasticity of demand,

- price,

- type of customer, and

- profit margin from sale.

It is important to match the length of the trade credit of a firm to its customer's capabilities. The enterprise giving the trade credit should take into account the purchasers' 
inventory conversion cycle as well as its accounts receivable conversion cycle. These two elements make up the operating cycle of a purchaser. The shorter this cycle, the shorter the maximum payment delay period offered to a purchaser should be. The maximum payment delay period for purchaser is the maximum expected period of accounts receivable cycle for a seller.

In order to choose what terms of sale should be proposed to the purchaser a firm management can use the incremental analysis as final criterion, as well as compare the influence of these proposals on firm value. Incremental analysis is a tool for estimating the effects of changes in trade credit policy on the enterprise. This analysis usually takes into account three basic elements:

(1) Estimation of the results of changes on sales as well as losses resulting from bad debts.

(2) Estimation of the changes in the firm accounts receivable level.

Cash investment in accounts receivable growth we have as:

$$
\begin{aligned}
& \triangle A A R=\left(A C P_{1}-A C P_{0}\right) \times \frac{C R_{0}}{360}+V C \times A C P_{1} \times \frac{C R_{1}-C R_{0}}{360}, \text { if } C R_{1}>C R_{0} \\
& \triangle A A R=\left(A C P_{1}-A C P_{0}\right) \times \frac{C R_{1}}{360}+V C \times A C P_{0} \times \frac{C R_{1}-C R_{0}}{360}, \text { if } C R_{1} \leq C R_{0}
\end{aligned}
$$

where $\triangle A A R=$ accounts receivable growth; $A C P_{0}=$ receivables collection period before trade credit policy change; $A C P_{1}=$ receivables collection period after trade credit policy change; $C R_{0}=$ cash from sales before trade credit policy change; $C R_{1}=$ cash from sales after trade credit policy change; and $V C=$ variable costs (in percent from sales incomes) ${ }^{2}$.

(3) Estimation of the firm value change:

$$
\begin{aligned}
\Delta E B I T= & \left(C R_{1}-C R_{0}\right) \times(1-V C)-k_{A A R} \times \Delta A A R-\left(l_{1} \times C R_{1}-l_{0} \times C R_{0}\right)- \\
& -\left(s p_{1} \times C R_{1} \times w_{1}-s p_{0} \times C R_{0} \times w_{0}\right)
\end{aligned}
$$

where $\triangle E B I T=$ earnings before interests and taxes growth; $k_{A A R}=$ operating costs of accounts receivable management in a firm; $l_{0}=$ bad debts loses before trade credit policy change; $l_{l}=$ bad debts loses after trade credit policy change; $s p_{0}=$ cash discount before trade credit policy change; $s p_{1}=$ cash discount after trade credit policy change; $w_{0}=$ part of purchasers using cash discount before trade credit policy change; and $w_{1}=$ part of purchasers using cash discount after trade credit policy change.

To check how changes in the accounts receivable level and EBIT influence the firm value, it is possible to use changes in future free cash flows. First we have changes in $F C F F$ in time 0 :

$$
\triangle F C F F_{0}=-\triangle N W C=-\triangle A A R
$$

Next the free cash flows to firm in periods (from 1 to $n$ ), as:

$$
\triangle F C F F_{1 \ldots n}=-\triangle N O P A T=-\triangle E B I T \times(1-T)
$$

Example 1. An enterprise $C R_{0}=8000000 € . V C=50 \% \times C R$. Operating costs of accounts receivable management in a firm, $k_{A A R}=20 \%$. WACC $=28 \%$. T $=19 \%$. Before trade credit policy change half of firm customers pay before delivery. $25 \%$ of them use $2 \%$ cash discount paying on the $12^{\text {th }}$ day. The remaining customers pay at the $25^{\text {th }}$ day. Bad

2 Although VC do not influence on the value of accounts receivables, it decides how much cash is tied in them. 
debts losses $3 \%$ of $C R^{3}$. The trade credit policy changes (from $2 / 12$, net 25 to $3 / 10$, net 45 ) considered by firm will result: $40 \%$ of firm customers will pay before delivery. $30 \%$ of them use $3 \%$ cash discount paying on the $10^{\text {th }}$ day. The remaining customers pay at the $45^{\text {th }}$ day. Bad debts losses $4 \%$ of $C R$. New $C R_{1}=10000000 €$. The effects of changes in trade credit policy would be felt for five years ${ }^{4}$.

Because $50 \%$ of sale before change of policy is done in cash, $25 \%$ on principle of collected on the $25^{\text {th }}$ day, $25 \%$ on principle of charge regulated up to the $12^{\text {th }}$ day, then the $A C P_{0}$ is:

$A C P_{0}=0,5 \times 0+0,25 \times 12+0,25 \times 25=9,25$ days.

The $A C P_{l}$ after change is:

$A C P_{1}=0,4 \times 0+0,3 \times 10+0,3 \times 45=16,5$ days.

That is why expected increase of average level of accounts receivable will be:

$\triangle A A R=(16,5-9,25) \times \frac{8000000}{360}+0,5 \times 16,5 \times \frac{2000000}{360}=206944 €$.

Therefore as a result of trade credit policy change, the average state of accounts receivable will grow for $206944 €$.

Next we have $\triangle E B I T$ :

$$
\begin{aligned}
\Delta E B I T= & 2000000 \times 0,5-20 \% \times 206944-(4 \% \times 10000000-3 \% \times 8000000) \\
& -(3 \% \times 10000000 \times 70 \%-2 \% \times 8000000 \times 75 \%)=708611 €
\end{aligned}
$$

Next we can estimate change in firm value:

$$
\Delta V=-206944+\frac{708611 \times 0,81}{0,28} \times\left(1-\frac{1}{1,28^{5}}\right)=1246364 € .
$$

As we can see, the trade credit policy change will increase the firm value. Similar information is given by estimation of $\triangle E V A^{5}$ after trade policy change:

$$
\triangle E V A=0,81 \times 708611-28 \% \times 206944=516031 € .
$$

As one can see through the discussed case, the first half and then $40 \%$ of sales are realized on the principle of cash sale with $2 \%$ or $3 \%$ discount for earlier payment. This results from the fact that those customers who created sales only for cash did not fulfill the requirements relating to the risks, which is considered as a percentage of delayed payments. Therefore, the firm stopped offering these purchasers sales on the principle of the trade credit. This was despite the fact that their financing with the trade credit made it possible to notice much greater activity and larger level of income from sales, than at the trade credit relinquishment.

3 Model supposes that uncollectible accounts receivable are tax deductible costs. Such rules are in authors country.

4 The horizon could be, according to firm's forecast finite or infinite and depends on information collected by management.

5 EVA is a registered trademark of Stern Stewart \& Co. 


\section{Portfolio Theory Approach in Trade Credit Decisions}

A portfolio is a set of assets (for example, accounts receivable). The portfolio approach to accounts receivable management can be used by utilizing the rate of profit (rate of advantage from assets) as one of the basic criteria that the firm giving the trade credit should encourage the purchaser to consider when making decisions (Jajuga, Jajuga, 1994, pp. $80-110)$. The profit rate resulting from the trade credit can be defined as:

$$
R_{n A R}=\frac{\Delta C R-\Delta \text { Costs }}{\Delta \text { Costs }}
$$

where $R_{n A R}=$ profit rate from giving the trade credit to purchasers $n, \Delta C R=$ cash from sales growth generated from additional sale to $n$ customers instead of the cash sale, and $\Delta$ Costs $=$ growth of costs resulting from offering the trade credit to purchaser $n$.

The present rate of profit is realized amid conditions of risk and uncertainty. The rate of profit changes varies according to the various probabilities. These probabilities result from customers' marketable situations which influence their ability to regulate their accounts payable to the seller in an appropriate manner. The risk measure connected with the accounts receivable of a particular purchaser varies according to the following equation:

$$
V=\sum_{i=1}^{m} p_{i} \times\left(R_{i}-R\right)^{2}
$$

where $p_{i}=$ based on historical data probability of $R_{i}$, and $R_{i}=$ expected rate of return from accounts receivable from the group of purchasers $i ; m-$ number of observations.

The measure of risk also can be defined according to standard deviation:

$$
s=\sqrt{V}=\sqrt{\sum_{i=1}^{m} p_{i} \times\left(R_{i}-R\right)^{2}}
$$

Both the variation and the standard deviation can be estimated for the historical data of a purchaser.

The next element is the correlation of profit from the trade credit given to the purchaser (or to the group of purchasers) in which the profits of the trade credit are given to other purchasers (or to different groups of purchasers). If the firm completes the transactions with more than one group of purchasers, it is possible to distinguish two or more homogeneous groups in relation to the risk and profit from giving the trade credit. In this case, the portfolio approach can be used. These groups can belong to definite $\operatorname{trades}^{6}$, and a connection does or can exist between the accounts receivables of these groups of purchasers. The measure of such a connection is usually a coefficient of correlation:

$$
\rho_{1.2}=\frac{\sum_{i=1}^{m} p_{i} \times\left(R_{1 i}-R_{1}\right) \times\left(R_{2 i}-R_{2}\right)}{s_{1} \times s_{2}}
$$

6 In Polish business practice purchasers coming from one trade group have similar payment because they serve the same market and have similar customers with similar payment habits. 
where $\rho_{1.2}=$ coefficient of first and second group of accounts receivable correlation; $R_{1}=$ expected rate of return from accounts receivable of the first group of purchasers; $R_{2}=$ expected rate of return from accounts receivable of the second group of purchasers; $s_{1}=$ standard deviation for the first group; $s_{2}=$ standard deviation for the second group; $R_{l i}=$ individual rate of return from accounts receivable of purchaser $i$ from the first group of purchasers; $R_{2 i}=$ individual rate of return from accounts receivable of purchaser $i$ from the second group of purchasers; and $p_{\mathrm{i}}=$ probability of individual rate of return from accounts receivable of purchaser $i$.

To show how portfolio approach can be used in accounts receivable management, we will use the portfolio of two groups of accounts receivable as example.

Example 2. The firm cooperates with two homogenous groups of purchasers. The first group of purchasers delivers its services to industry A, the second group of purchasers serves customers from industry B. Creating a portfolio of two kinds of accounts receivable makes sense only when the correlation between profits from the giving trade credit for these groups is less than 1 .

Example 2, Case 1. Correlation coefficient between accounts receivable profits from Groups A and B equals $1, \rho_{A, B}=1$.

Fig. 2 The profit - risk relation for portfolio of accounts receivable for two groups of purchasers if $\rho_{A, B}=1$

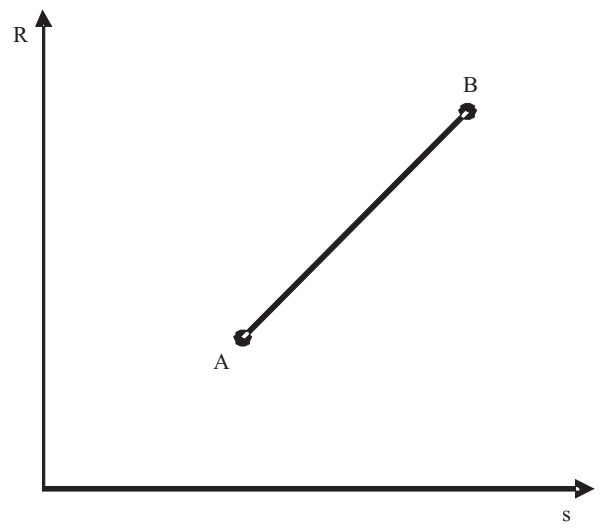

Source: own study on basis (Jajuga, Jajuga, 1994).

Figure 2 shows that there is no possibility of increasing profit from diversification without increasing risk if

Example 2, Case 2. Coefficient of correlation equal $(-1), \rho_{A, B}=(-1)$. Perfect negative correlation.

At Point A we offer trade credit only to Group A. At point B we offer trade credit to Group B. If we are following from Point A (and we are enlarging contribution of Group B in accounts receivable portfolio) to $\mathrm{A} / \mathrm{B}_{1}$, the risk $s$ is decreasing and the profit $R$ is increasing. As we see in Figure 3, it makes no sense to possess accounts receivable only from Group A. It is because with identical risk $s$, the portfolio $\mathrm{A} / \mathrm{B}_{2}$ offers higher profit $R$. 
Fig. 3 The profit - risk relation for portfolio of accounts receivable for two groups of purchasers if $\rho_{A, B}=(-1)$

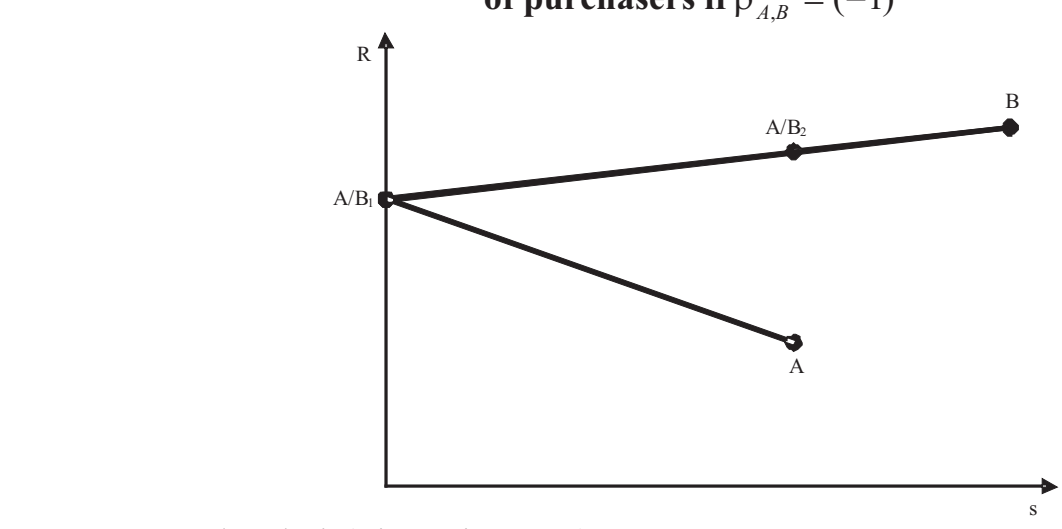

Source: own study on basis (Jajuga, Jajuga, 1994).

Example 2, Case 3. Coefficient of correlation equal 0, It is a situation when benefits from giving trade credit to Group A and Group B are not related to each other in any way.

Fig. 4 The profit - risk relation for portfolio of accounts receivable for two groups of purchasers if $\rho_{A, B}=0$

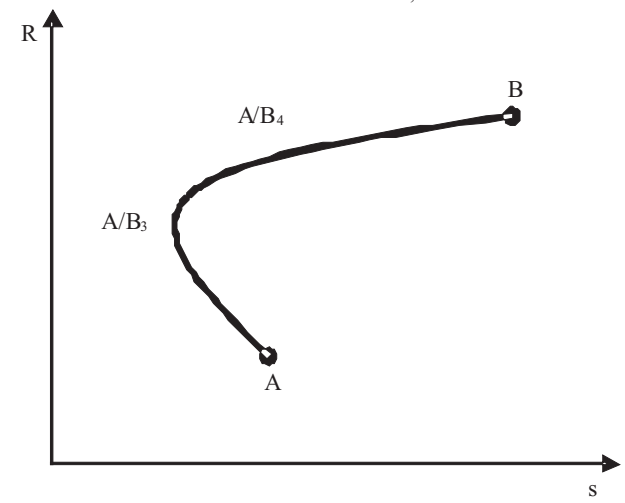

Source: own study on basis (Jajuga, Jajuga, 1994).

In such a situation the only possible is a partial reduction of risk. The reasonable firm should not choose any portfolio of charge lying on the $A-A / B_{3}$ line, because it is always possible to find more profitable equivalent on: $\mathrm{A} / \mathrm{B}_{3}-\mathrm{A} / \mathrm{B}_{4}$ line, which with the same risk $s$ gives higher profit $R$. The skilful construction of two groups of accounts receivable portfolio can lead to a considerable reduction of risk. The inclusion to single-asset portfolio second component, almost always leads to risk decreasing, sometimes even with simultaneous profit growth (Brigham, Daves, p. 77).

Example 3 (continuation of example 1). After the historical data analysis had been achieved, firm managers noticed that the expected profits were higher and correlated negatively with profits generated from purchases by current customers. This was certainly from allowing trade credit to customers who had made cash purchases because of the high risk during the receivables collection period. These trends lead to the expectation ${ }^{7}$ of a lower risk of profits from accounts receivable and growth in profits from sales in

7 With admittance of taking both groups simultaneously on trade credit principles. 
general at the same time. A 3\% cash discount was proposed for customers who paid within 10 days along with an extension of the payment deadline to 45 days for any remaining customers. As a result, $5 \%$ of sales would be paid for with in cash while $40 \%$ of customers would take advantage of the cash discount by paying by the $10^{\text {th }}$ day. Remaining customers ( $45 \%$ of sales) would make their payments on the $45^{\text {th }}$ day. Bad debts $=1 \% \times C R . C R_{1}=$ $12000000 €$. The effect of these changes in trade credit policy would be felt for five years. In addition, $V C$ would be reduced from $50 \%$ to $48 \%$ thanks to the positive advantages of scales resulting from larger sales (and increased production).

So, we have:

$$
\begin{aligned}
A C P_{2}= & 0,05 \times 0+0,50 \times 10+0,45 \times 45=25,25 \text { days } \\
\triangle A A R= & (25,25-9,25) \times \frac{8000000}{360}+0,48 \times 25,25 \times \frac{4000000}{360}=490222 € . \\
\Delta E B I T= & 4000000 \times 0,52-20 \% \times 490222-(1 \% \times 12000000-3 \% \times 8000000) \\
& -(3 \% \times 12000000 \times 55 \%-2 \% \times 8000000 \times 75 \%)=2023956 €
\end{aligned}
$$

From this, we have the following change in the firm value:

$$
\Delta V=-490222+\frac{2023956 \times 0,81}{0,28} \times\left(1-\frac{1}{1,28^{5}}\right)=3660760 € \text {. }
$$

The firm value will increase. The proposed change will be more profitable than in example 1 without using the portfolio approach. This related information comes from the estimation of EVA change:

$$
\triangle E V A=0,81 \times 2023956-28 \% \times 490222=1502142 € .
$$

\section{Conclusions}

Accounts receivable management decisions are very complex. On the one hand, too much money is tied up in accounts receivables, because of an extreme liberal policy of giving trade credit. This burdens the business with higher costs of accounts receivable service with additional high alternative costs. Additional costs are further generated by bad debts from risky customers. On the other hand, the liberal trade credit policy could help enlarge income from sales. In the article, the problem was linked to the operational risk of purchasers interested in receiving trade credit who, as separately considered groups, may characterize too high risk level. However, if they are considered as one of several groups of enterprise customers, and if their payment habits are correlated with the payment habits of the remaining groups, what was formerly impossible could become possible, and may even turn profitable. The portfolio of assets, like the portfolio of accounts receivables, sometimes presents a lower risk to acceptable advantages than the independently considered groups of purchasers.

\section{References}

BIERMAN, H.; HAUSMAN, W. H. 1970. The Vredit Granting Decision. Management Science, vo. 16, no 8, Apr. 1970, pp. B519-532.

BRIGHAM, E.; P. DAVES, Intermediate Financial Management, Thomson, Mason 2004.

FABOZZI, F.; FONG, G. 2000. Zarzqdzanie portfelem inwestycji finansowych przynoszacych staly dochód. Warszawa : WN PWN, 2000. 
FRIEDLAND, S. 1966.The Economics of Corporate Finance, Eglewood Clifs, New Yersey, Prentice Hall, 1966.

JAJUGA, K. 1993. Zarzqdzanie kapitałem. Wrocław : Wydawnictwo Akademii Ekonomicznej we Wrocławiu, 1993.

JAJUGA K.; JAJUGA, T. 2002. Inwestycje. Instrumenty finansowe. Ryzyko finansowe. Inżynieria finansowa. Warszawa : WN PWN, 2002.

JAJUGA K.; JAJUGA T. 1994. Jak inwestować w papiery wartościowe. Warszawa : WN PWN, 1994.

JAJUGA, K.; KUZIAK, Katarzyna; MARKOWSKI, Paweł. 1997. Inwestycje finansowe. Wrocław : Wydawnictwo AE, 1997.

LEWELLEN,W. G.; EDMISTER, R. O. A 1973. General Model for Accounts Receivable Analysis and Control, Journal of Financial and Quantitative Analysis, March 1973, pp. 195- 206.

LEWELLEN, W. G.; JOHNSON R. W. 1972. Better Way to Monitor Accounts Receivable. Harward Business Review, May- June 1972, pp. 101- 109.

LUENBERGER, D. 2003. Teoria inwestycji finansowych. Warszawa : WN PWN, 2003.

MANESS, T.; ZIETLOW, J. Short-Term Financial Management. Fort Worth. Dryden Press, 1998.

MICHALSKI, G. Leksykon zarzadzania finansami. Warszawa : C. H. Beck, 2004.

PIOTROWSKA,. M. Finanse spółek. Krótkoterminowe decyzje finansowe. Wrocław : Wydawnictwo AE, 1997.

PLUTA, W.; MICHALSKI, Grzegorz. 2005. Krótkoterminowe zarzadzanie kapitałem. Warszawa : C. H. Beck, 2005.

PRINGLE, J. J.; COHN,. R. A. 1974. Steps Toward on Integration of Corporate Financial Theory, Readings on the Management of Working Capital, ed. K. V. Smith, St. Paul, Minnesota, West Publishing Company, 1974.

REILLY, F.; BROWN, K. 2001. Analiza inwestycji i zarzadzanie portfelem. Warszawa : PWE, 2001.

ROBISHEK, A. A.; TEICHROEW, D.; JONES, J. M. 1965. Optimal Short-Term Financing Decision. Management Science, 1965, vol. 12, no 1, ser. A, Sciences, , pp. 1- 36.

SCHERR, F. 1989. Modern Working Capital Management. Text and Cases. Englewood Cliffs : Prentice Hall, 1989.

\title{
Determinants of Accounts Receivable Level: Portfolio Approach in Firm's Trade Credit Policy
}

\begin{abstract}
Trade credit management should contribute to realization of basic financial purpose of an enterprise which is the is maximization of its value. Many of the current asset management models that are found in financial management literature assume book profit maximization as the basic financial purpose. These book profit-based models could be lacking in what relates to maximization of enterprise value. The enterprise value maximization strategy is executed with a focus on risk and uncertainty. This article presents the consequences that can result from operating risk that is related to purchasers using payment postponement for goods and/or services. The present article offers a method that uses portfolio management theory to determine the level of accounts receivable in a firm. An increase in the level of accounts receivables in a firm increases both the net working capital and the costs of holding and managing accounts receivables.
\end{abstract}

Keywords: accounts receivable, trade credit management, incremental analysis, value based management, portfolio analysis.

JEL classification: G32, P33, P34. 